RU Формирование грамотности работы с обратной связью при обучении иностранному языку студентов высшей школы

\author{
Заруцкая Е. B.
}

\begin{abstract}
Аннотация. Цель исследования - теоретическое и практическое обоснование возможности формирования грамотности работы с обратной связью у студентов высшей школы при обучении иностранному языку. В статье уточняется научное содержание понятия «педагогическая обратная связь» и описывается практический опыт формирования грамотности работы с обратной связью на занятиях по иностранному языку в ходе взаимооценивания устной монологической речи при помощи платформы Flipgrid. Научная новизна состоит в обосновании возможности использования инструмента взаимооценивания для формирования всех составляющих грамотности работы с обратной связью при условии планирования петли обратной связи и проведения вводного тренинга. В результате проведенного исследования описаны роли преподавателя и студента в формировании грамотности работы с обратной связью, уточнены предложенные исследователями Д. Баудом и Д. Карлессом составляющие грамотности работы с обратной связью применительно к обучению иностранному языку и подведены итоги первичного опыта организации работы студентов по сообщению и получению обратной связи в процессе взаимооценивания устных монологических высказываний на платформе Flipgrid.
\end{abstract}

\title{
EN Developing University Students' Feedback Literacy When Teaching a Foreign Language
}

Zarutckaia E. V.

\begin{abstract}
The paper justifies the potential of "Foreign Language" discipline when developing university students' feedback literacy. The article reveals the content of the term "pedagogical feedback" and describes the author's experience of developing students' feedback literacy in foreign language classes during peer assessment of students' monologues on the Flipgrid platform. The scientific originality of the study involves justifying the potential of using peer assessment as a tool of developing feedback literacy among university students on the condition that a feedback loop is created and introductory training is conducted. The research findings are as follows: the author describes teacher and student roles in the development of feedback literacy, clarifies the feedback literacy model (D. Boud, D. Carless) in relation to foreign language teaching, summarizes the experience of organizing students' feedback activity involving giving and receiving feedback in a foreign language when assessing peers' monologues on the Flipgrid platform.
\end{abstract}

\section{Введение}

Актуальность темы исследования определяется несколькими факторами. Во-первых, каждому преподавателю знакома ситуация, когда подробная обратная связь, предоставленная студентам на их письменную или устную работу, в том числе с описанием сильных и слабых сторон и/или предложениями по улучшению качества созданного ими учебного продукта, не приводила к желаемому результату, то есть студенты в дальнейшей учебной деятельности повторяли те же ошибки и не учитывали предыдущие комментарии преподавателя при выполнении сходных по формату заданий. Следовательно, вопрос о том, какой должна быть обратная связь, чтобы после ее получения студент корректировал свое учебное поведение и улучшал результаты своей работы, является открытым.

Во-вторых, изменившиеся условия преподавания иностранного языка, а именно использование дистанционного формата обучения и увеличение количества студентов в группе, диктуют необходимость поиска новых инструментов донесения обратной связи до студентов, а также способов организации их работы с полученной обратной связью. 
Данные факторы определили задачи описываемого в настоящей статье исследования:

1. уточнить роль преподавателя и студента в формировании грамотности работы с обратной связью;

2. охарактеризовать четыре составляющие грамотности работы с обратной связью в контексте обучения иностранному языку;

3. описать первичный практический опыт формирования грамотности работы с обратной связью при взаимооценивании устной монологической речи студентов на занятиях по иностранному языку.

В работе были применены следующие методы научного исследования: изучение и теоретический анализ литературы по педагогике, методике преподавания иностранных языков, менеджменту, управлению организациями; обобщение личного педагогического опыта.

Теоретическую базу исследования составили научные работы отечественных и зарубежных авторов: А. А. Коренева (2018) о соотношении педагогической и академической обратной связи; Д. Бауда (Carless, Boud, 2018; CRADLE, 2019), Д. Карлесса (Carless, 2019; Carless, Boud, 2018; CRADLE, 2019; Winstone, Carless, 2020), Э. Моллоу (CRADLE, 2019), Н. Уинстоун (CRADLE, 2019; Winstone, 2019; Winstone, Carless, 2020), А. Липневич, Д. Берга, Дж. К. Смита (Lipnevich, Berg, Smith, 2016) о новой парадигме обратной связи в высшей школе; Д. Стоуна и Ш. Хин (Stone, Heen, 2015) об особенностях восприятия обратной связи. Коммуникативные модели сообщения обратной связи рассматривались в работах зарубежных исследователей по теории коммуникации и управлению организациями: Ш. Харли (Harley, 2013) и М. Уоррел (https://www.forbes.com/sites/margiewarrell/2015/11/04/how-to-criticizewell/?sh=5b562fd26476). Вопросы организации процесса обмена обратной связью между равными по статусу участниками в ходе взаимооценивания исследовались в трудах Л. В. Вилковой и П. Н. Грибовой (Вилкова, Грибова, 2021), Н. Ф. Лиу и Д. Карлесса (Liu, Carless, 2006).

Практическая значимость исследования состоит в возможности применения преподавателями-практиками описанного в данной статье опыта организации работы с обратной связью в процессе обучения устной монологической речи на иностранном языке студентов высшей школы на платформе Flipgrid.

\section{Роль преподавателя и студента в формировании грамотности работы с обратной связью}

Обратная связь в самом широком понимании представляет собой «любую информацию, которую мы получаем о себе» или то, «как мы узнаем о самих себе из нашего опыта и от других людей» (Stone, Heen, 2015, с. 4). В рамках данной статьи будет описываться опыт развития умений формулировать обратную связь в устной или письменной форме и работать с ней в ходе обучения иностранному языку, поэтому уточним, что педагогическая обратная связь предполагает получение студентами уже не «любой» информации о себе, а той, которая предоставляется «в ответ на определенные действия в процессе образования» и соотносится «с процессами обучения и воспитания» (Коренев, 2018, с. 118).

Ряд зарубежных исследователей (Carless, Boud, 2018; CRADLE, 2019; Winstone, 2019) занимают более категоричную позицию в вопросе содержательного наполнения данного термина и подчеркивают, что обратная связь не исчерпывается сообщением и получением информации от одного субъекта учебного процесса другому. В частности, Д. Бауд отмечает, что если обратная связь не приводит к изменению в поведении студента (того, как он думает или действует после ее получения), не развивает умения или понимание студента, то это просто «информация», поскольку обратная связь обязательно предполагает, что после ее получения «что-то происходит по-другому» (цит. по: CRADLE, 2019). Следовательно, в рамках данной статьи будем считать, что помимо сообщения информации о ценности созданного студентами учебного продукта или предложений по улучшению его качества педагогическая обратная связь также включает в себя процесс «осмысления» полученной информации самим студентом и его ответные «действия по использованию данной информации» в последующей учебной и образовательной деятельности (Carless, Boud, 2018, с. 1316). Только в таком случае можно утверждать, что студент умеет грамотно работать с обратной связью.

Очевидно, что при таком понимании термина «обратная связь» ответственность за организацию работы с ней лежит не только на преподавателе, но и на студентах. Так, преподаватель управляет процессами сообщения и получения обратной связи между всеми участниками образовательного процесса и заранее планирует оценочные задания таким образом, чтобы студент мог использовать комментарии на свою работу в будущем для, как минимум, улучшения качества той же работы или, как максимум, коррекции своих учебных действий при работе с подобными оценочными заданиями в последующих модулях (Carless, 2019, с. 706). Следовательно, «петля обратной связи» (Carless, 2019) должна тщательно планироваться преподавателем заранее, так как если оценочное задание приходится на конец модуля или семестра и больше не повторяется, то студент не будет иметь возможности отреагировать на полученный комментарий о результатах своей работы и применить его на практике (CRADLE, 2019).

Роль студента также изменяется, поскольку он перестает рассматриваться исключительно как пассивный получатель обратной связи, который ожидает от преподавателя оценочного комментария о качестве своей работы или прямого указания на то, как ее улучшить (Winstone, 2019). Студент должен при необходимости принимать на себя ответственность за инициирование получения обратной связи на свою работу от всех участников образовательного процесса, а также реагировать на нее и использовать полученный комментарий в своей последующей учебной деятельности для улучшения качества создаваемых учебных продуктов и коррекции учебного поведения в целом (Carless, 2019; CRADLE, 2019). Таким образом, для того, чтобы студенты могли принимать новую для себя роль и извлекать максимальную пользу из обратной связи, их необходимо обучать грамотно работать с ней. 


\section{Составляющие грамотности работы с обратной связью применительно к обучению иностранному языку}

В основу данного исследования положен подход, разработанный Д. Баудом и Д. Карлессом (Carless, Boud, 2018, с. 1319), которые выделяют четыре составляющие грамотности работы с обратной связью (feedback literacy):

1) признание ценности обратной связи, поступающей из разных источников;

2) вынесение суждения о работе (своей и других участников образовательного процесса);

3) управление эмоциональной реакцией в случае получения негативной обратной связи (сохранение эмоционального равновесия и избегание тактики самозащиты);

4) способность к действию в ответ на поступившую обратную связь.

Уточним, как данные составляющие грамотности работы с обратной связью могут развиваться при обучении студентов высшей школы иностранному языку.

Как видим, первая и третья составляющие грамотности работы с обратной связью связаны с умениями воспринимать и принимать обратную связь, вторая - наоборот, с умением формулировать обратную связь в устной или письменной форме, четвертая - с последующими учебными и образовательными действиями. Следовательно, если мы хотим формировать грамотность работы с обратной связью на занятиях по иностранному языку, то нам необходимо давать студентам возможность выступать как в роли отправителей обратной связи, так и в роли ее получателей.

Охарактеризуем каждую составляющую грамотности работы с обратной связью подробнее.

Признание студентами ценности обратной связи возможно только в случае осознанного желания с их стороны критически посмотреть на свою работу, готовности признать ее сильные и слабые стороны (CRADLE, 2019) и обдумать, какую пользу могут принести полученные комментарии для их дальнейшей учебной деятельности. Другими словами, признание ценности обратной связи тесно связано с навыками критического мышления и сопутствующими критически мыслящему человеку личностными качествами (как минимум, открытости к чужому мнению и готовности признать свои ошибки). При этом важно подготовить студента к пониманию того, что одинаковую ценность для него могут представлять комментарии, получаемые как от преподавателя, так и от равных по статусу участников, то есть других студентов. Э. Моллой (CRADLE, 2019) подчеркивает, что, анализируя работы друг друга, студенты, как правило, оценивают их под другим углом, чем преподаватель и/или эксперт, добавляя, тем самым, новую перспективу, еще один угол зрения, что и делает обратную связь от равных по статусу участников ценной.

Вынесение суждения о работе (своей или чужой) связано с процессом рефлексии. Именно поэтому считается (Carless, Boud, 2018, с. 1320), что формулирование комментариев на работу однокурсника приносит студенту большую пользу, чем получение комментариев, поскольку сам по себе процесс формулирования суждения довольно когнитивно-затратный, подразумевающий подключение мышления более высокого уровня и задействующий умения диагностировать проблему и предлагать какие-то решения. К тому же ознакомление с работой однокурсника дает студенту возможность поразмышлять и над своей собственной работой, проанализировать, какие методы и подходы работают, а какие нет (Вилкова, Грибова, 2021, с. 11).

Обмен обратной связью между равными по статусу участниками (peer feedback) может рассматриваться в качестве отдельного вида учебной деятельности, когда студенты формулируют суждения о работах друг друга без выставления баллов, то есть количественной оценки, а может сопровождаться присвоением баллов (Lіu, Carless, 2006, с. 2). Наша многолетняя практика организации обмена обратной связью между студентами в ходе взаимооценивания на занятиях по иностранному языку показывает, что, во-первых, студенты достаточно легко выставляют баллы на работы однокурсников, но испытывают трудности при формулировании сопроводительного комментария с обратной связью, который бы обосновывал выставленный балл; во-вторых, отдельные студенты при присвоении баллов в ходе оценивания работ однокурсников руководствуются не только критериями оценивания выполненного задания, но и своими личными отношениями с автором оцениваемой работы и/или другими личными мотивами; в-третьих, ценность комментария на работу для студента-получателя обратной связи снижается после того, как баллы были выставлены. Следовательно, если цель задания научить студентов формулировать обратную связь в устной или письменной форме и осмысленно реагировать на нее, то представляется целесообразным предоставлять студентам возможность практиковать данные умения без количественного измерения, то есть без выставления баллов по заданным критериям.

Важно отметить, что сами по себе критерии оценивания важны, так как помогают студенту сформулировать сравнительное суждение о своей работе или работе однокурсника. Однако окончательное суждение-комментарий о работе партнера должно выноситься в форме обобщенного мнения, расширенного описания своей точки зрения с предоставлением деталей и примеров (Вилкова, Грибова, 2021, с. 11). В практике менеджмента и управления организациями считается, что детали и примеры важны, поскольку получатели обратной связи могут извлечь из нее пользу и адекватно отреагировать на обратную связь, только если она обладает следующими характеристиками: конкретностью, направленностью на процесс, а не на личность получателя обратной связи, честностью и ориентированностью на изменения в будущем (https://zapier.com/blog/how-to-giveeffective-feedback/). Очевидно, что описанные характеристики применимы и к описанию педагогической обратной связи, именно поэтому студентов необходимо знакомить с характерными чертами обратной связи в процессе обучения формулированию суждений о работах однокурсников. 
В управленческой литературе предлагается несколько, в том числе авторских, коммуникативных моделей предоставления обратной связи (Harley, 2013; https://www.ddiworld.com/solutions/behavioral-interviewing/starmethod; https://www.forbes.com/sites/margiewarrell/2015/11/04/how-to-criticize-well/?sh=5b562fd26476). Полагаем, что многие из них представляют значительный интерес и для практики обучения иностранному языку, причем не только в обучении студентов управленческих специальностей, поскольку освоение алгоритма формулирования сообщения положительной и в особенности негативной обратной связи способствует развитию коммуникативных умений и умений межличностного общения любого специалиста. Следование данным коммуникативным моделям позволяет донести до получателя обратной связи информацию таким образом, чтобы привлечь внимание к конкретным аспектам содержания работы или деятельности и вместе с тем максимально снизить эмоциональную нагрузку сообщения. Все это в равной степени важно и для педагогической обратной связи, так как тон, с которым доносится обратная связь до студента, - один из главных аспектов, определяющих реакцию студента на обратную связь (Lipnevich, Berg, Smith, 2016).

Коммуникативные модели предоставления обратной связи могут использоваться на занятиях по иностранному языку в качестве речевых образцов и рассматриваться как особый коммуникативный жанр. В частности, интерес могут представлять структурно-композиционные особенности высказывания, используемые в нем нормы вежливости и, конечно, языковые клише и фразы.

Управление эмоциональной реакцией в случае получения негативной обратной связи - это скорее задача психологии, чем методики обучения иностранному языку. Однако необходимо признать, что, во-первых, как уже было сказано выше, обучение студентов формулировать конкретные и объективные суждения о работах друг друга в коммуникативно приемлемой форме будет, если не прямо, то косвенно, помогать им спокойнее воспринимать обратную связь и, тем самым, выносить из нее для себя пользу. Во-вторых, также очевидно, что чем чаще студент будет получать обратную связь в процессе обучения, тем больше он будет упражняться в адекватном эмоциональном реагировании на нее.

Способность студента к действию в ответ на поступившую обратную связь может подготавливаться со стороны преподавателя путем планирования преемственности и взаимосвязанности оценочных заданий, на которые будет даваться обратная связь, так, чтобы полученный комментарий на одно задание мог использоваться студентом при выполнении следующего задания.

Таким образом, можно сделать вывод о том, что при организации процесса сообщения и получения обратной связи на занятиях по иностранному языку в ходе взаимооценивания у студентов могут развиваться все составляющие грамотности работы с обратной связью, выделенные Д. Баудом и Д. Карлессом (Carless, Boud, 2018).

\section{Практический опыт формирования грамотности работы с обратной связью на занятиях по иностранному языку при взаимооценивании устной монологической речи}

Организация процесса формирования грамотности работы с обратной связью осуществлялась в ходе дистанционного обучения английскому языку 67 студентов-первокурсников управленческих специальностей СПбГу во втором семестре 2020-2021 учебного года. Уровень владения английским языком (B2 и C1 (по CEFR)) позволял студентам попеременно выступать в роли отправителей и получателей обратной связи и упражняться в вынесении суждения, формулировании комментария и реагировании на комментарий партнера.

В соответствии с представленными выше составляющими грамотности работы с обратной связи были выделены задачи обучения:

- дать студентам понимание ценности получаемой обратной связи;

- ознакомить студентов с моделями сообщения обратной связи и сформировать умение формулировать собственное суждение о работе однокурсника с опорой на данные модели;

- ознакомить студентов с причинами, по которым обратная связь может восприниматься негативно, и организовать практику получения обратной связи, в которой будут отмечаться как положительные, так и отрицательные характеристики выполненной работы;

- запланировать петлю обратной связи таким образом, чтобы студенты могли использовать полученную в комментарии информацию для изменения своей работы и/или коррекции своего последующего учебного поведения.

В самом начале семестра проводился вводный тренинг (четыре академических часа), на котором рассматривались вопросы отличия обратной связи от критики и похвалы; описывались характеристики обратной связи (конкретность, направленность на процесс, а не на личность получателя обратной связи и т.д.); разбирались коммуникативные модели сообщения обратной связи: STAR (https:/www.ddiworld.com/solutions/behavioralinterviewing/star-method), ACED (https://www.forbes.com/sites/margiewarrell/2015/11/04/how-to-criticize-well/?sh= 5b562fd26476), «сэндвич» и др., обсуждались причины, по которым обратная связь может восприниматься негативно. Далее студенты практиковались в написании комментария с опорой на одну из изученных ранее коммуникативных моделей сообщения обратной связи на основе кейсов из своей академической жизни.

После вводного тренинга содержание обучения включало в себя три тематических модуля в течение семестра, каждый из которых оканчивался итоговым устным оценочным заданием: устным монологическим высказыванием. Так как студенты обучались дистанционно, для выполнения оценочного задания и обмена обратной связью была выбрана платформа Flipgrid (https://info.flipgrid.com/), позволяющая записывать видеомонологи и давать обратную связь на них другим студентам в форме видеокомментария или письменного комментария. Таким образом, каждому студенту предлагалось записать пятиминутный видеомонолог 
(в соответствии с предложенным заданием), после этого просмотреть видеомонолог однокурсника и дать развернутую обратную связь в форме видео или письменного комментария с подкреплением своего высказывания конкретными деталями и примерами. Всего в течение семестра каждым студентом было записано три пятиминутных видеомонолога и дана обратная связь на три работы однокурсников.

Студенты оценивали видео-монологи друг друга по двум параметрам - «Идеи» (“Ideas”) и «Выполнение» (“Performance”), но не выставляли друг другу баллы - только формулировали комментарий с обратной связью. Преподаватель, в свою очередь, оценивал и выставлял баллы как за монолог, так и за предоставленную обратную связь. Комментарий с обратной связью оценивался преподавателем по трем критериям: конкретность (иллюстрация примерами), соблюдение (по возможности) баланса положительное-отрицательное, следование нормам вежливости. Таким образом, максимальное количество баллов, которое студенты могли получить за устный или письменный комментарий, - три.

После получения обратной связи от однокурсника у студента была возможность обдумать его и при желании к следующему занятию перезаписать свой видеомонолог с учетом представленных замечаний или пожеланий однокурсника. В этом случае итоговому оцениванию со стороны преподавателя подлежал второй исправленный вариант монолога. Следовательно, петля обратной связи планировалась таким образом, чтобы, во-первых, после получения обратной связи от партнера каждый студент мог при желании внести изменения в свое монологическое высказывание (перезаписать его), а во-вторых, сохранить преемственность и взаимосвязанность оценочных заданий в течение семестра так, чтобы студенты могли использовать замечания и рекомендации, поступившие от партнера, при выполнении оценочного задания в следующем модуле.

Платформа Flipgrid имеет ряд преимуществ, вследствие которых она и была выбрана для организации работы с обратной связью. Так, например, она:

- дает возможность записать всем студентам видеомонологи (оценочное задание) на одной платформе;

- позволяет предоставить как устную (в виде видеосообщения), так и письменную (в виде письменного комментария) обратную связь на работу одного или нескольких студентов;

- предоставляет студенту возможность самому регулировать настройки приватности, в результате этих действий устный или письменный комментарий с обратной связью может быть виден всем студентам группы или только тому студенту, которому он предназначен.

Ограничения платформы Flipgrid заключаются в том, что:

- письменный комментарий ограничен по длине 500 знаками. Следовательно, чтобы дать развернутую обратную связь, студенту необходимо разбить комментарий на несколько комментариев;

- преподавателю видно количество просмотров, но не видно, кто из студентов просмотрел видеомонолог и просмотрел ли комментарий с обратной связью на свою работу автор работы.

Перед выполнением оценочных заданий второго и третьего модулей студентам предлагалась рекомендация (Guidelines), один из пунктов которой был сформулирован следующим образом: «еред записью своего монолога вернитесь снова к обратной связи, которую Вы получили от студента своей группы в предыдущем (-их) модуле (-ях). Перечитайте этот комментарий и определите, чем он может быть полезен Вам при выполнении задания в этом модуле. Если Вы согласны с рекомендациями и замечаниями, высказанными в комментариях к предыдущей работе, постарайтесь учесть их при выполнении этого задания».

Первичный опыт использования обратной связи можно считать положительным, так как студенты формулировали комментарии на работы однокурсников, которые отвечали требованиям, предъявяемым к обратной связи (конкретность, ориентированность на изменение в будущем и т.д.), и соотносились критериям оценивания. Те студенты, комментарии которых не соответствовали одному или нескольким критериям, получали более низкий балл за выполненную работу. В целом комментарии студентов были подробными и помогали понять получателю обратной связи его сильные и слабые стороны и на уровне идей, и на уровне исполнения.

Вместе с тем было выявлено несколько проблем, которые требуют дальнейшей рефлексии и поиска практических решений.

Первая: 3-5\% студентов перезаписывали монолог после получения обратной связи в каждом модуле, при этом 13-19\% студентов (из тех, кто не перезаписал монолог) в ответном письменном комментарии благодарили однокурсника, предоставившего обратную связь, за конструктивную критику и за предложения по улучшению работы. Следовательно, преподавателю было понятно, что данные студенты по крайней мере прочитали обратную связь и каким-то образом ее обдумали, а в случае повторной записи своего монолога, еще и учли ее в своей работе. Информацию о других студентах преподаватель мог получить только отсрочено, то есть тогда, когда студенты приступят к оценочному заданию в следующем модуле и либо учтут при выполнении работы предыдущий комментарий другого студента-отправителя обратной связи, либо нет.

При выполнении оценочных заданий во втором и третьем модулях отдельные студенты повторяли те же ошибки. Преподавателю не было понятно, с чем это связано: 1) с тем, что студент не прочитал / не посмотрел комментарий; 2) с тем, что студент не понял комментарий с обратной связью; 3) с тем, что студент по какимто своим причинам сознательно решил не использовать комментарий в своей дальнейшей работе и т.д.

Вторая: в первом модуле не все комментарии студентов соответствовали трем критериям оценивания, поэтому преподавателю приходилось давать подробную «обратную связь на обратную связь», в результате чего студент, получающий обратную связь, может получить неполный или некачественный комментарий на свою работу, что также, несомненно, увеличивает объем работы преподавателя. Вместе с тем необходимо признать, что количество неполных или некачественных комментариев от студентов к третьему модулю значительно снизилось. 
Таким образом, практика организации работы с обратной связью на занятиях по иностранному языку показала, что в процессе взаимооценивания устных монологических высказываний на платформе Flipgrid у студентов могут формироваться все составляющие грамотности работы с обратной связью.

\section{Заключение}

В результате проведенного исследования мы пришли к трем основным выводам:

- вследствие переосмысления термина «обратная связь» в педагогической науке и практике стало очевидно, что ответственность за формирование грамотности работы с обратной связью несут и преподаватель, и студент;

- характеристика составляющих грамотности работы с обратной связью выявила, что содержание обучения иностранному языку может планироваться таким образом, чтобы студенты развивали все четыре составляющие: признавали ценность обратной связи, выносили суждение о работе друг друга, управляли эмоциями при получении обратной связи и отвечали действием в ответ на обратную связь;

- первичный практический опыт показал, что при организации процесса взаимооценивания устных монологических высказываний на платформе Flipgrid студенты могут практиковаться в развитии всех составляющих грамотности работы с обратной связью при условии планирования петли обратной связи и проведения предшествующего практике вводного тренинга.

Перспективы дальнейших исследований могут быть связаны с изучением вопросов развития грамотности работы с обратной связью в средней школе, сопоставлении особенностей работы с обратной связью в онлайн и офлайн обучении, а также развитии умений студентов высшей школы формулировать не только педагогическую, но и академическую обратную связь.

\section{Источники | References}

1. Вилкова Л. В., Грибова П. Н. Организация процесса взаимооценивания на старшем этапе средней школы // Научный потенциал. 2021. № 2 (33).

2. Коренев А. А. Обратная связь в обучении и педагогическом общении // Rhema. Рема. 2018. № 2.

3. Carless D. Feedback Loops and the Longer-Term: Towards Feedback Spirals // Assessment \& Evaluation in Higher Education. 2019. Vol. 44. № 5.

4. Carless D., Boud D. The Development of Student Feedback Literacy: Enabling Uptake of Feedback // Assessment \& Evaluation in Higher Education. 2018. Vol. 43. № 8.

5. CRADLE. CRADLE in Conversation: Student Feedback Literacy: the Current Landscape and Future Horizons [видео]. 2019. URL: https://blogs.deakin.edu.au/cradle/2019/10/30/recording-now-available-cradle-in-conversationstudent-feedback-literacy-international-panel/

6. Harley Sh. How to Say Anything to Anyone: A Guide to Building Business Relationships That Really Work. Austin: Greenleaf Book Group Press, 2013.

7. Lipnevich A. A., Berg D., Smith J. K. Toward a Model of Student Response to Feedback // Handbook of Human and Social Conditions in Assessment / ed. by G. T. L. Brown, L. Harris. N. Y.: Routledge, 2016.

8. Liu N. F., Carless D. Peer Feedback: The Learning Element of Peer Assessment // Teaching in Higher Education. 2006. Vol. 11. Issue 3.

9. Stone D., Heen Sh. Thanks for the Feedback: The Science and Art of Receiving Feedback Well. L.: Portfolio Penguin, 2015.

10. Winstone N. MIC National Forum Seminar 1 Feb (Full Presentation) [видео]. 2019. URL: https://www.youtube. com/watch?v=Fo8MvDfzluQ

11. Winstone N., Carless D. Designing Effective Feedback Process in Higher Education: A Learning-Focused Approach (Research into Higher Education). L. - N. Y.: Routledge, 2020.

\section{Информация об авторах | Author information}

RU Заруцкая Екатерина Витальевна ${ }^{1}$, к. пед. н.

${ }^{1}$ Санкт-Петербургский государственный университет

EN Zarutckaia Ekaterina Vitalievna ${ }^{1}, \mathrm{PhD}$

${ }^{1}$ Saint Petersburg University

${ }^{1}$ e.zarutskaia@spbu.ru

\section{Информация о статье | About this article}

Дата поступления рукописи (received): 16.08.2021; опубликовано (published): 29.10.2021.

Ключевые слова (keywords): педагогическая обратная связь; грамотность работы с обратной связью; обучение иностранным языкам; взаимооценивание; высшая школа; студенты; pedagogical feedback; feedback literacy; foreign language teaching; peer assessment; university; students. 